\title{
Occlusion of Water Pores Prevents Guttation in Older Strawberry Leaves
}

\author{
Fumiomi Takeda ${ }^{1}$, Michael E. Wisniewski², and D.M. Glenn ${ }^{3}$ \\ U.S. Department of Agriculture, Agricultural Research Service, Appalachian Fruit Research \\ Station 45 Wiltshire Road, Kearneysville, WV 25430 \\ Additional index words. Fragaria $\times$ ananassa, low-temperature electron microscopy, hydathode
}

\begin{abstract}
Hydathodes of young, folded strawberry (Fragaria $\times$ ananassa Duch.) leaves had unoccluded water pores With various sized apertures, as observed by low-temperature scanning electron microscopy. Hydathodes of fully expanded leaves were brownish and the water pores within the hydathodes were covered with a solid material, presumably comprised of epicuticular waxes and substances excreted through the hydathodes. The entire water pore area of the hydathode was occasionally covered with a shield-like plate. The shield-like plate over the hydathode water pores impeded water flow even with an induced positive pressure. Mechanical scraping of the hydathode area eliminated impedance to water conduction. These observations suggest that external occlusion of water pores in the hydathodes is the resistance component associated with the absence of guttation in older strawberry leaves.
\end{abstract}

Strawberry leaves can exude xylem fluid through the water pores of hydathodes (guttation). The function of hydathodes and the relationship of guttation to plant water relations and growth are not fully understood. Kramer (1969) considered guttation of only incidental importance, but Klepper and Kaufmann (1966) suggested that guttation serves for mineral nutrition when transpiration is suppressed, solutes being absorbed from the guttation water as it moves upward in the plant. Tipburn in emerging strawberry leaves, caused by a localized deficiency of $\mathrm{Ca}$, occurs least in plants grown under conditions, that favor guttation (Bradfield and Guttridge, 1979). In several species of plants, an exudate is deposited over the water pores and a gummy material accumulates in the intercellular spaces of the epithem as leaves mature (Fahn, 1979; Maeda and Maeda, 1987; Mortlock, 1952). Such processes in Fragaria sp. or in other rosaceous plants have not been described.

Strawberry plants guttate under conditions of high humidity, low transpiration, and adequate soil moisture. Under field conditions, guttation is an indicator of high plant water status and soil water availability (Fahn, 1979; Faiz, 1983; Glenn and Takeda, 1989). Guttation occurred when predawn leaf water potential (PLWP) of strawberry was above $-0.07 \mathrm{MPa}$ and absent when PLWP was below - 0.11 MPa (Glenn and Takeda, 1989). Only the young expanding leaves and not the older leaves consistently guttated with high PLWP conditions. However, PLWP or solute potential was not significantly different between leaves of varying ages within a plant, suggesting that the absence of guttation in older leaves was associated with an increased resistance to water flow through the hydathodes or a loss of vascular functions in the older leaves.

Donnelly and Skelton (1987) described the hydathode structure of micropropagated plantlets and relatively young leaves of greenhouse-grown strawberry plants. However, we found no information on the anatomy of hydathodes in the leaves of fieldgrown strawberry plants. Tissue preparation for light micros-

Received. for publication 1 Mar. 1991. Mention of a trademark or proprietary products does not constitute a guarantee or warranty of the products by the USDA and does not imply its approval to the exclusion of other products that may also be suitable. The cost of publishing this paper was defrayed in part by the payment of page charges. Under postal regulations, this paper therefore must be hereby marked advertisement solely to indicate this fact.

'Research Horticulturist.

${ }^{2}$ Plant Physiologist.

${ }^{3}$ Soil Scientist. copy and scanning electron microscopy (SEM) generally involves processing methods whereby many soluble materials may be extracted by solvents (water, ethanol, acetone, etc.). Cryofixation techniques for SEM allow for the observation of a specimen without extraction of biological material from the tissue sample.

The objective of our study was to characterize the differences in hydathodes of young, guttating, and older, nonguttating strawberry leaves using light microscopy and low-temperature scanning electron microscopy (LTSEM).

\section{Materials and Methods}

Low-temperature scanning electron microscopy. Leaves of field-grown 'Allstar' strawberry plants were used in the study. Young, guttating and older, nonguttating leaves were harvested at $0700 \mathrm{HR}$ and were placed in a plastic bag containing a wet paper towel.

Tissue sections 2 and $3 \mathrm{~mm}^{2}$, containing the leaf margin and the hydathode region, were mounted on an aluminum stub using adhesive tape. An Oxford CT-1500 Cryo-Preparation System and Cold Stage (Oxford, England) mounted on a Cambridge S120 scanning electron microscope (Cambridge, England) were used. Samples were quenched in liquid $\mathrm{N}_{2}$ slush, transferred to the cold stage, and etched at $-80 \mathrm{C}$ until surface ice had sublimated. The samples were then removed from the specimen chamber, coated with gold/palladium at $-160 \mathrm{C}$ and subsequently transferred back to the cold stage and kept at -165 to - 175C. Specimens were viewed at 5 to $10 \mathrm{kV}$.

Light microscopy. Tissue samples $\left(1 \mathrm{~mm}^{2}\right)$ were placed in $3 \%$ (v/v) gluteraldehyde in $25 \mathrm{~mm}$ sodium phosphate buffer $(\mathrm{pH}$ 6.8 ) at 4C. Samples were dehydrated in a graded ethanol series, followed by propylene oxide and embedded in Spurr's epoxy resin. The material was sectioned with a glass knife at 1 to 2 $\mu \mathrm{m}$, mounted on a glass slide, and stained with $0.5 \%$ toluidine blue $\mathrm{O}(\mathrm{w} / \mathrm{v})$ in $0.1 \%$ sodium carbonate $(\mathrm{w} / \mathrm{v}), \mathrm{pH} 11.1$ (O'Brien and McCully, 1981).

Pressurization of leaves in Scholander pressure chamber. The petiole of older, nonguttating leaves was placed in deionized water within a Scholander pressure chamber (Scholander et al., 1965), with the leaf blade left outside the chamber. After 10 min of pressurization at $0.3 \mathrm{MPa}$, during which time no droplets of water appeared at the tips of the serrated margins, the external hydathode areas were disturbed with a gentle mechanical scraping using a knife blade to determine whether this step would result in exudation of water. 


\section{Results and Discussion}

Tips of leaf serrations of young, expanding field-grown strawberry leaves had an achlorophyllous area; older, nonguttating leaves were brown to amber on the serration tips. LTSEM examination of the subapical region of leaf serration revealed that hydathodes were located on the, adaxial surface (Fig. 1) The water pores in young, guttating leaves were slightly opened (Fig. 2). In and around these water pores, epiphytic bacteria and yeasts were occasionally observed (Fig. 3 ). There were $\approx 50$ to 100 water pores visible per hydathode in fully expanded leaves (Fig. 1). This quantity contrasts with that of hydathodes of in vitro-grown strawberry plantlets that contain $\approx 10$ to 20 apertures that are always open (Donnelly and Skelton, 1987). Regardless of the size of hydathodes, water pore density appeared to be $\approx 1300 / \mathrm{mm}^{2}$.

Occlusion of water pore apertures was evident in completely unfolded, nonguttating leaves (Fig. 4). The occlusion probably resulted from the gradual deposition and accumulation of substances secreted through the water pore apertures and the deposition of epieuticular wax and crystalline materials on the surface (Fig. 5). In some nonguttating leaves the water pores had become completely covered with these substances, forming a platelike shield over the entire hydathode (Fig. 6). Occasionally, round, sunken areas in the shield were observed that indicated the location of the water pores (Fig. 7). In wheat, plugging of water pores occurred due to the deposition of residual material from the evaporation of exudate at the water pore (Maeda and Maeda, 1987).

Cellular organization in the epithem region (Esau, 1977) consisted of a modified mesophyll of loosely arranged, irregularshaped cells (Figs. 8 and 9). Cells in the epithem were smaller than those within the palisade and spongy mesophyll. A trans-
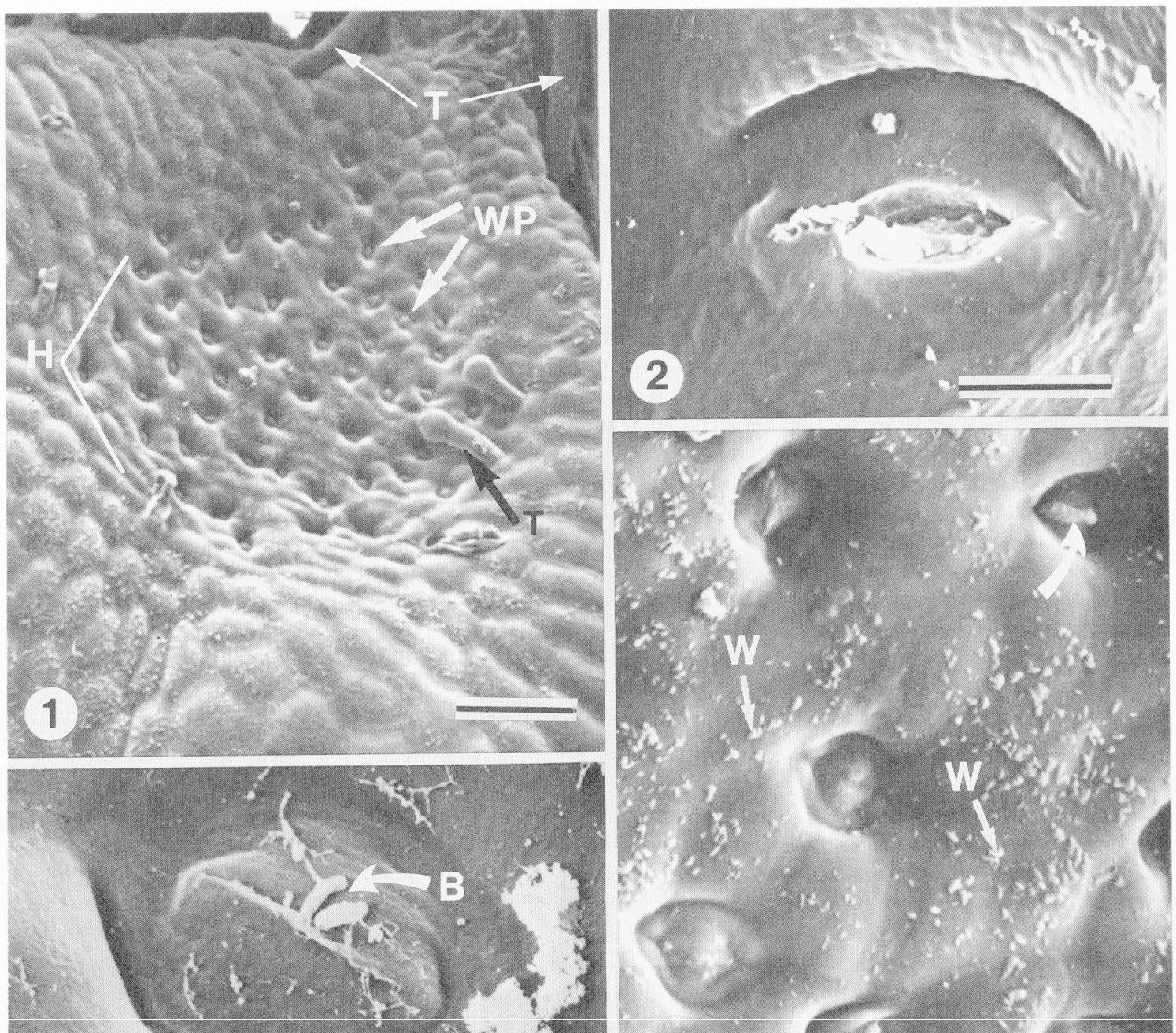

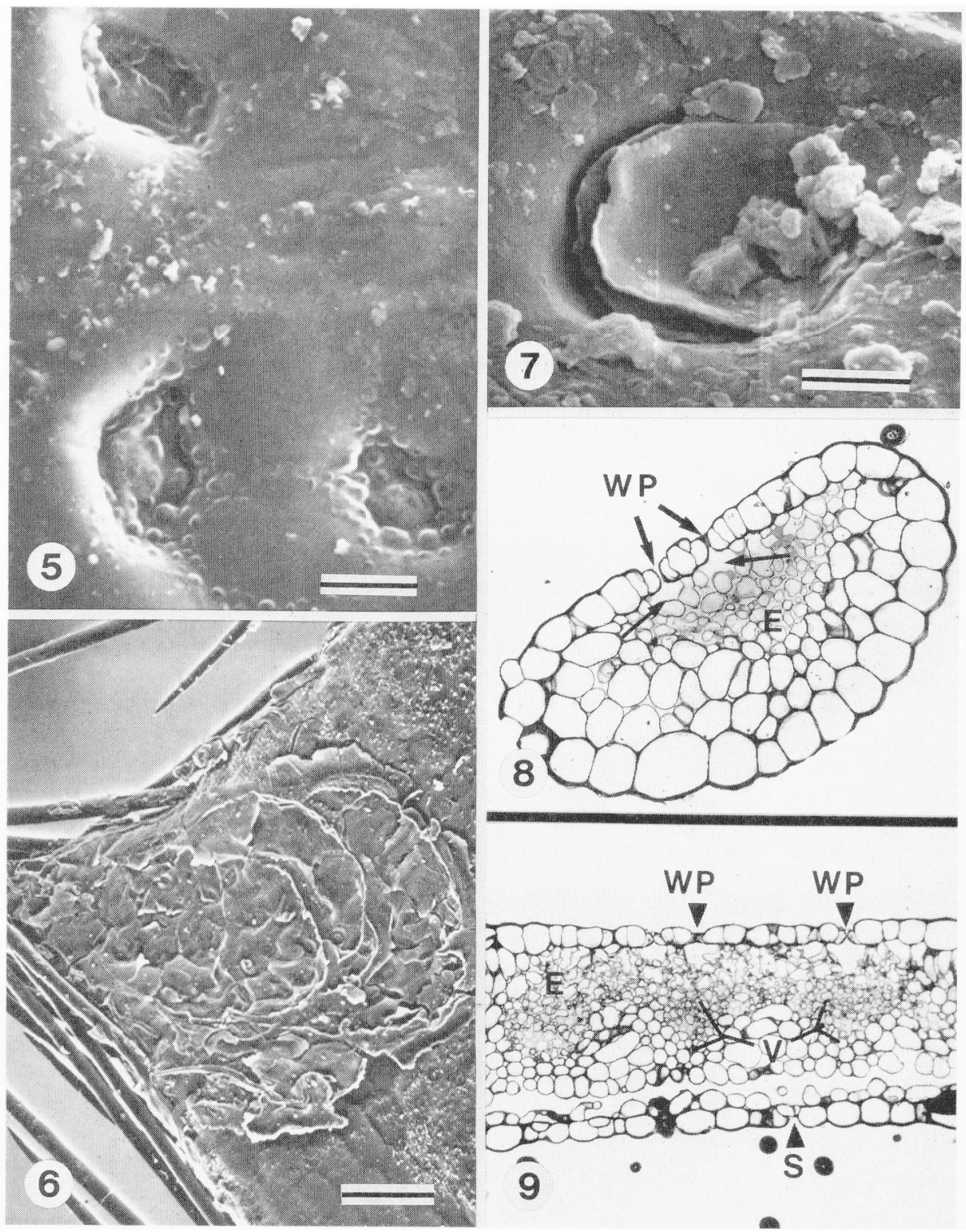

Figs. 5-9. (5) Downward view of a hydathode from a mature, nonguttating leaf. Note the water pore apertures are occluded by additional deposition of substances. Bar $=5 \mu \mathrm{m}$. (6) Foliar apex of a nonguttating leaf. Note the hydathode is completely covered by a shield-like plate formed by accumulation of epicuticular wax and excreted solids. Bar $=150 \mu \mathrm{m}$. (7) Higher resolution detail than in (6) of the shieldlike plate covering the water pore area of the hydathode of a nonguttating leaf. Occasionally, the deposition of substances above the water pore zone had circular, sunken areas indicating the location of occluded water pores below. Bar $=5 \mu$ m. (8) Cross section of the margin tip from a young strawberry leaf. Section shows the hydathode with water pores (WP) on the adaxial surface and the epithem (E) below. Note the cavity below the water pore (arrow) and the small, irregularly shaped cells of the epithem $(\times 806)$. (9) Cross section of the margin tip from a "mature strawberry leaf that was not guttating at the time of collection. Section shows the hydathode with its water pores (WP) on the adaxial surface. The epithem $(\mathrm{E})$ of mature leaves is more polychromatic and is comprised of numerous compact, irregular cells. The lower limit of epithem is undulating and is where vascular bundles (V) are located. A stoma (S) is on the abaxial surface $(\times 412)$.

verse section through a hydathode showed that under each water characterized by irregular cell shapes in the epithem and a not- 
were cut $2 \mathrm{~mm}$ from the hydathode, water flow was immediately visible from the cut end, indicating that the resistance component was not in the leaf blade. Alternatively, when the hydathodes of nonguttating leaves were scraped, a film of water formed immediately over the disturbed area. These observations indicate that the cessation of guttation, in older strawberry leaves is due to the surface occlusion of water pores.

In conclusion, this study has demonstrated that: 1) cessation of guttation in older strawberry leaves is associated with the deposition of substances over the water pores, and 2) the occlusion of water pores provides a sufficient impedance to the flow of water from the xylem, through the epithem and water pores, to leaf surface. Under conditions conducive for guttation, water droplets appeared on the margins of young, expanding leaves but not on older leaves. The repeated occurrence of guttation and subsequent evaporation of the liquid deposited solid substances over the water pores. This process led to the dysfunction of hydathodes and eventual cessation of guttation in mature strawberry leaves.

\section{Literature Cited}

Bradford, E.G. and C.G. Guttridge. 1979. The dependence of calcium transport and leaf tipburn in strawberry on relative humidity and nutrient solution concentration. Ann. Bot. 43:363-372.
Donnelly, D.J. and F.E. Skelton. 1987. Hydathode structure of micropropagated plantlets and greenhouse-grown 'Totem' strawberry plants. J. Amer. Soc. Hort Sci. 112:755-759.

Esau, K. 1977. Anatomy of seed plants, 2nd ed. Wiley, New York. p. 205-206.

Fahn, A. 1979. Secretary tissue in plants. Academic, New York. p. $2-23$.

Faiz, S.M.A. 1983. Use of pressure bomb in the determination of soil water potential. Plant \& Soil 73:257-264.

Glenn, D.M. and F. Takeda. 1989. Guttation as a technique to evaluate the water status of strawberry. HortScience 24:599-601.

Klepper, B. and M.R. Kaufmann. 1966. Removal of salt from xylem sap by leaves and stems of guttating plants. Plant Physiol. 41:17431747.

Kramer, P.J. 1969. Plant and soil water relationships: A modern synthesis. McGraw-Hill, New York. p. 165-167.

Maeda, E. and K. Maeda. 1987. Ultrastructural studies of leaf hydathodes. 1. Wheat (Triticum aestivum) leaf tips. Jpn. J. Crop Sci. 65:641-651.

Mortlock, C. 1952. The structure and development of the hydathodes of Ranunculus fluitans Lam. New Phytol. 51: 129-138.

O'Brien, T.P. and M.E. McCully. 1981. The study of plant structure: Principles and selected methods. Termarcarphi Press, Melbourne, Austraia.

Scholander, P.F., E.D. Broadstreet, and E.A. Hemmingsen. 1965. Sap pressure in vascular plants. Science 148:339-346. 